УДК 336 JEL G32

DOI 10.26425/1816-4277-2018-1-136-140

Пепоян А.Л.

АКТУАЛЬНЫЕ ПРОБЛЕМЫ ОЦЕНКИ
ИМУЩЕСТВЕННОГО КОМПЛЕКСА
ОРГАНИЗАЦИИ

Аннотация. Определена актуальность рассматриваемой темы, раскрыто содержание основных понятий в соответствии с действующим законодательством Российской Федерачии. Указаны исторические аспекты формирования практики оценочной деятельности в связи с развитием рыночных процессов, отражена основная теоретическая основа оченочной деятельности. Рассматриваются особенности регулирования системы взаимодействия банков, кредиторов и оченщиков. Обсуждаются существуюшие недочеть в используемой на сегодняшний день методологии оценки объектов недвижимости, рассматриваются варианты их систематизации и адаптации под нынешнюю рыночную конъюнктуру.

Ключевые слова: имущество, имущественный комплекс, предприятие, оборотные активы, внеоборотные активы, оценочная деятельность.

Pepoyan Avetis

\title{
ACTUAL PROBLEMS OF ASSESSING THE PROPERTY COMPLEX OF THE ORGANIZATION
}

Annotation. The urgency of the topic is determined; the content of the basic concepts is disclosed in accordance with the current legislation of the Russian Federation. The historical aspects of forming appraisal practice in connection with the development of market processes are pointed out, the main theoretical basis of valuation activity is reflected. Regulation system interaction between banks, creditors and appraisers are considered. The existing shortcomings in the methodology used today to assess real estate are discussed. The options for their systematization and adaptation to the current market conditions are examined.

Keywords: property, property complex, enterprise, current assets, non-current assets, appraisal activity.

Тема имущества и имущественных отношений стала актуальной в начале 1990 г. после смены экономической системы и начала процесса приватизации государственной и муниципальной собственности. Из-за отсутствия методологии оценки государственного имущества часть из нее была несправедливо распределена, что привело к дисбалансу в рыночной системе, необоснованному возникновению предприятий с огромными долями рынка в крупных отраслях и, как следствие, к нездоровой конкуренции. Оценочная деятельность в России и на сегодняшний день связана с рядом проблем, в частности, недостаточно глубоко изучена и разработана методологическая база оценки различных объектов, отсутствует детализованная классификация объектов недвижимости.

В условиях острой рыночной конкуренции имущество становится одним из определяющих факторов продуктивной деятельности предприятия. Именно имущество в совокупности является инструментом создания дополнительной стоимости. Эффективное управление имуществом представляет собой сложную задачу, решение которой увеличивает имущественный потенциал организации, но прежде чем говорить об имущественном потенциале организации и его оценке, необходимо определить само понятие имущества и имущественного комплекса, а также место имущественного комплекса в системе гражданских отношений. «Имущество - материальный объект гражданских прав, прежде всего, права собственности; совокупность имущественных прав (актив) или имущественных прав и обязанностей (актив+пассив), принадлежащих определенному лицу» [6, с. 25]. Отсюда вытекает понятие имущественного комплекса (далее - ИК), который представляет не просто случайный набор имущественных элементов, а определенную совокупность имущества, которая представляет собой систему и используется по определенному назначению.

\footnotetext{
(C) Пепоян А.Л., 2018
} 
Согласно п.1 статьи 132 Гражданского кодекса Российской Федерации (далее - ГК РФ) предприятием как объектом прав признается имущественный комплекс, используемый для осуществления предпринимательской деятельности. В целом же, как имущественный комплекс, согласно этой же статье, предприятие признается недвижимостью [1]. Таким образом, предприятие - имущественный комплекс, в состав которого входит наряду с недвижимым (прежде всего земельными участками и их частями, зданиями, сооружениями) и движимым имуществом (оборудование, инвентарь), обязательственные права требования и пользования, долги (обязанности), некоторые исключительные права (фирменное наименование, товарные знаки, знаки обслуживания)? а также другие исключительные права. Статья 132 ГК РФ не содержит полного списка элементов, которые могут быть включены в состав предприятия, поэтому состав имущественного комплекса, определяющий его как предприятие, формируется индивидуально в каждой ситуации в зависимости от направления деятельности предприятия, финансово-экономических, политических и других условий. В общем виде состав ИК предприятия представлен на рисунке 1. Данный список элементов ИК демонстрирует сложный состав предприятия, что делает оценку его имущественного потенциала весьма непростой задачей.

Институт профессиональной оценки объектов недвижимости в нашей стране начал формироваться в 19921993 гг. и продолжает развиваться в настоящее время по следующим направлениям.

1. Деятельность некоммерческих организаций оценщиков, которые включены в единый государственный реестр саморегулируемых организаций оценщиков (далее - СРОО). Это профессиональное объединение оценщиков на условиях членства. Самыми крупными в России СРОО являются Российское общество оценщиков (далее - РОО), Лига независимых оценщиков и Институт независимых оценщиков.

2. Деятельность независимых оценщиков и оценщиков, действующих в рамках специализированных юридических организаций. В настоящее время в России насчитывается несколько тысяч профессиональных оценщиков [4].

Саморегулируемой организацией оценщиков является некоммерческая организация, которая создана для целей регулирования и контроля деятельности своих участников. Первым и самым большим в России профессиональным объединением специалистов в области оценки является Общероссийская общественная организация «Российское общество оценщиков». Оно создано с целью объединения субъектов оценочной деятельности, создания оптимальной среды для их профессиональной деятельности и защиты прав и интересов его членов. [7].

«Под оценочной деятельностью понимается профессиональная деятельность субъектов оценочной деятельности, направленная на установление в отношении объектов оценки рыночной, кадастровой, ликвидационной, инвестиционной или иной предусмотренной федеральными стандартами оценки стоимости» [2]. «Объекты оценки, перечисленные в законе, принято классифицировать следующим образом: движимые и недвижимые объекты, объекты интеллектуальной собственности, предприятие (бизнес) как объект оценки» [3]. Оценочную деятельность могут осуществлять как отдельные частные лица в статусе индивидуального предпринимателя, так и на основании трудового договора между оценщиком и юридическим лицом, которое зарегистрировано в законодательно установленном порядке. Однако вне зависимости от того занимается ли специалист частной практикой или выступает от имени юридического лица, субъект оценочной деятельности обязан застраховать свою ответственность, а также являться членом одной из саморегулируемых организаций оценщиков.

Оценочная деятельность является достаточно сложной, требует наличия достоверной информации об объекте оценки и профессиональных знаний специалиста. Очевидно, что для наиболее объективной оценки требуется детальная оценка каждого элемента ИК, которые являются весьма разнородными, а их оценка требует применения различных методов и механизмов. На сегодняшний день классическая теория говорит о существовании трех основных подходов к определению стоимости ИК предприятия: затратного, сравнительного и доходного.

Доходный метод в определении стоимости базируется на оценке текущей стоимости доходов предприятия за определенный промежуток времени в будущем в случае его эффективного функционирования или на цене, за которую данное предприятие может быть реализовано на рынке. Существует ряд обстоятельств и признаков предприятия, которые делают его оценку доходным методом затруднительным. Так, например, если данное предприятие занимается фондоемким и материалоемким производством, не представлено широко на рынке, если оно представляет собой объект специфической деятельности, а коммерческая цель не является основополагающей при его создании (предприятия культуры, медицинские учреждения, научные организации), тогда оценка такой организации может быть произведена затратным методом. Затратный подход основывается на определении стоимости фактических 
издержек, связанных с созданием оцениваемого предприятия (строительство с учетом коэффициента износа и амортизации, ввод объекта в эксплуатацию и так далее).

Можно выделить два случая, когда применение затратного подхода необходимо:

- компании, зарегистрированные в форме АО и ГУПов, финансовые схемы которых являются достаточно сложными и непрозрачными;

- применение затратного в совокупности с другими методами, прежде всего с доходным, позволяет получить наиболее объективный результат оценки и увеличить эффективность инвестиционных решений.

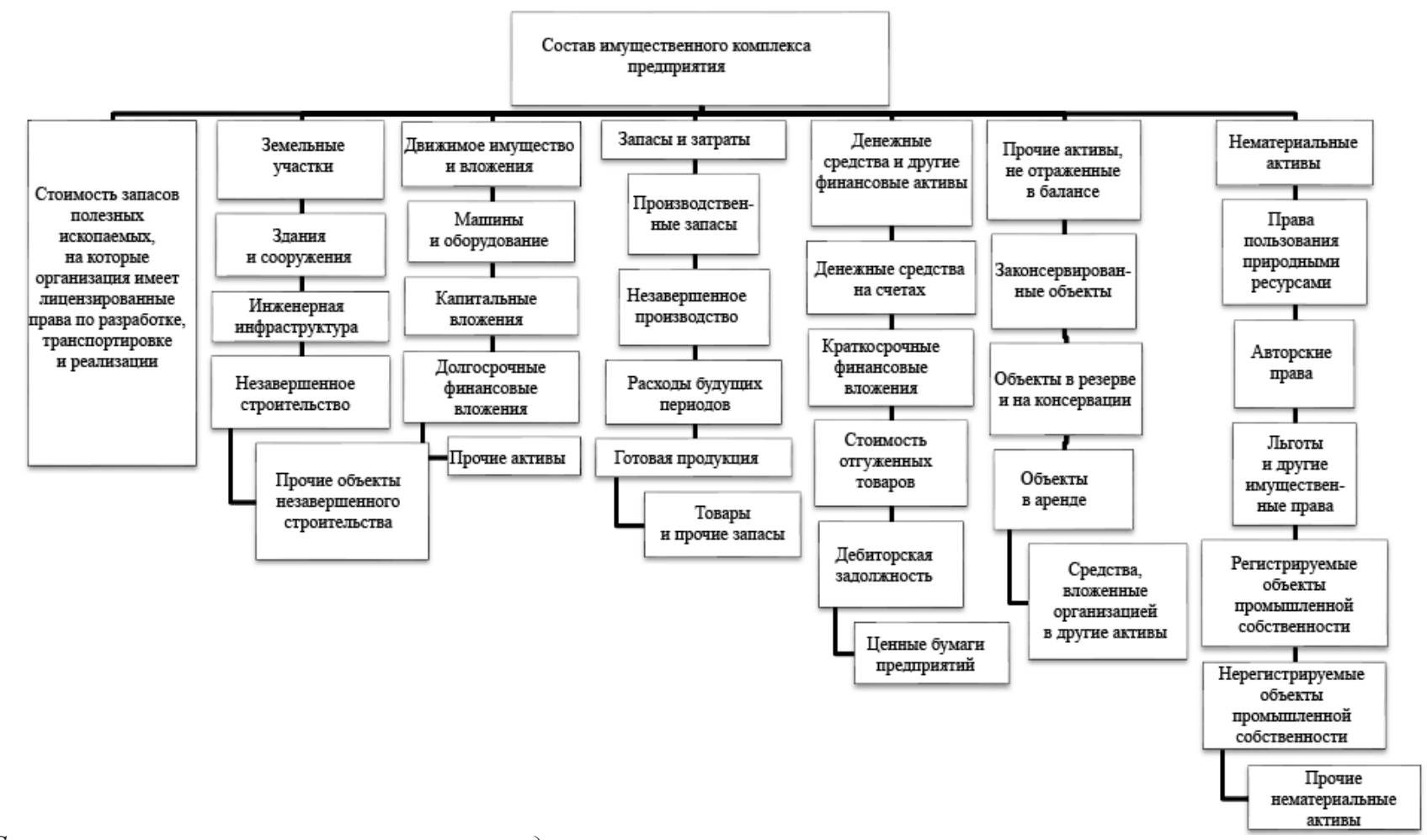

Составлено автором по материалам исследования

Рис. 1. Состав имущественного комплекса предприятия

Применение сравнительного метода наиболее рационально в случае наличия широкого рынка оцениваемого товара, когда существует большое предложение данного товара. Сравнительный метод основывается на сопоставлении однородных оцениваемому товаров, которые уже были реализованы на данном рынке. Когда речь идет об оценке уникальных, единичных товаров, то применяется затратный подход. В теории результаты оценки объектов должны быть одинаковыми вне зависимости от метода оценки, однако фактор несовершенности рынков приводит к тому, что данные могут отражать расхождения в показателях стоимости, рассчитанных с использованием различных подходов. Все три классических подхода к оценке объектов предполагает использование присущего ему метода оценки. Например, при сравнительном подходе чаще всего используют метод отраслевых коэффициентов, метод сделок и метод рынка капитализации. Метод чистых активов (NAV) и метод ликвидационной стоимости (LV) присущ затратному подходу. Когда при оценке используется доходный подход, как правило, выбирают метод капитализации или метод дисконтирования денежных потоков (DCF) [5].

Отметим, что помимо указанных выше традиционных методов оценки ИК в последние годы достаточно широко используется новый подход - опционный. Данный способ оценки учитывает фактор изменчивости внешней среды и фактор наличия альтернативных решений, что позволяет пошагово в динамике получить наиболее эффективный результат, но в данной статье мы не будем останавливаться на опционном методе, так как это достаточно содержательная теория.

В отечественной практике оценочной деятельности встречались самые различные ситуации, и для того чтобы выбрать подходящий метод оценки, необходимо произвести строгую классификацию объектов оценки по 
различным факторам: тип сделки, момент сделки, объект оценки и так далее. Несмотря на наличие сложившейся законодательной базы и более чем двадцатилетней практики оценочной деятельности, в России отсутствует обобщенный инструментарий комплексной оценки ИК. Создание подобного механизма в России представляет сложность ввиду наличия ряда проблем, связанных с особенностями отечественных экономических и политических процессов. На мой взгляд, основными проблемами, которые мешают качественному развитию оценочной деятельности в России, является большое разнообразие объектов оценки (существенные отличия в их составе и структуре), отсутствие унифицированных требований к оценочной деятельности, сложность процесса оценки объектов для целей залога и кредитования (взаимодействие с банками), недоработанные механизмы компенсации убытков. Для реформации оценочной деятельности требуется принятие организационных мер. В сфере оценки ИК предприятия выделение алгоритма комплексной оценки поможет решить ряд проблем. По мнению автора, комплексная оценка ИК предприятия должна состоять из нескольких последующих действий:

- анализ полезности использования элементов ИК (с позиции соответствия производственной мощности и производственной программе компании);

- разработка и принятие решений по увеличению или уменьшению имущественного потенциала;

- выбор методов решения поставленной задачи;

- комплексная оценка имущества;

- оценка эффективности использования имущественного и производственного потенциала организации.

Комплексная оценка имущества сначала должна проводиться поэлементно по группам ИК, при этом возможно использование различных методов: затратного, доходного и сравнительного. Для оценки ОС, как правило, применяют затратный метод. Другие элементы лучше оценивать по уровню доходности. Комплексная оценка возможна на базе интегрального показателя, который включает объем затрат и удельный вес данного конкретного показателя в общей стоимости имущества.

Эффективность использования ИК может базироваться на использования различных показателей рентабельности. Производственный потенциал организации определяется как совокупность имущественного комплекса и стоимости рабочей силы. Эти два показателя постоянно находятся в движении, и если стоимость ИК в первом приближении можно определить по балансу организации, то стоимость рабочей силы зависит от отраслевой принадлежности, региона, применяемых форм оплаты труда на конкретном предприятии, минимальный размер оплаты труда (МРОТ) на конкретный момент времени, устанавливаемого Правительством Российской Федерации. Точная достоверная оценка ИК требует объективных данных, в противном случае результаты оценки ИК будут искажены, что может привести к серьезным последствиям, связанным с имущественным ущербом. Полезность использования ИК определяется, прежде всего, соответствием его состояния структуре выполняемых работ или номенклатуре выпускаемой продукции. При этом должны учитываться следующие факторы: степень загрузки основных средств, коэффициент использования машин и механизмов во времени и по мощности, соотношение основного и оборотного капитала, подбор наиболее эффективных источников формирования и обеспечения прироста оборотных средств, где основное внимание должно уделяться выбору форм и методов кредитования организации и подбору банка-агента. Если в процессе анализа будут выявлены лишние или временно неиспользуемые ресурсы, необходимо решать вопрос либо об их ликвидации или консервации, либо поэлементной замене отдельных основных средств. Увеличение или уменьшение имущественного потенциала связано с динамикой объемов выполняемых работ. Проблема заключается в том, что в строительстве постоянно меняется номенклатура строящихся объектов. Строительные организации, как правило, в начале планового года не имеют полной картины договоров на весь период и, как следствие, стоимостных показателей по объемам. Если возникает необходимость увеличения имущественного потенциала, должна решаться задача по поиску реальных средств для приобретения дополнительных основных фондов и увеличения оборотных активов. Решить эту задачу возможно посредством применения лизинга и банковского кредитования. При выборе методов главным критерием должно быть соотношение затрат и результатов. Самым сложным является привлечение дополнительных финансовых источников. Для решения этого вопроса могут быть использованы заемные или привлеченные средства соинвесторов на взаимовыгодных условиях. Для этого необходимо определить гарантии или наличие поручителей, которые возьмут на себя инвестиционные риски. На взгляд автора, наиболее эффективным инструментом является механизм лизинга, поскольку ОС, используемые в строительстве имеют чрезвычайно высокую единичную стоимость и длительные сроки эксплуатации. Особенно это касается импортной техники. При этом основное внимание должно быть уделено выбору 
методов начисления амортизации, так как амортизационные начисления являются основной составляющей лизинговых платежей. Следовательно возникает проблема оптимизации размеров лизинговых платежей, что обязательно должно учитываться в договоре лизинга.

Мы знаем, что в современной экономике банки играют очень важную роль. Практически ни одна крупная сделка, в том числе и с ИК, не обходится без участия финансовых учреждений. В подобных случаях банки нуждаются в максимально качественной оценке объектов для принятия инвестиционных решений. Система взаимодействия банков, кредиторов и оценщиков также требует разработки мер регулирования, так как она является лакомым источником дохода для недобросовестных рыночных субъектов. Причем практика показывает, что нарушения выявляются с обеих сторон. Банку далеко не всегда выгодно занижать стоимость предмета залога, так как в целом это ограничивает объем кредитования, a, следовательно, и объем дохода. Основное давление на оценщиков оказывается со стороны собственников имущества с целью максимизации стоимости предмета залога, что становится одной из основных причин появления ложных отчетов. Это приводит к снижению степени доверия банков к субъектам оценочной деятельности и необходимости дополнительной проверки на достоверность отчетов любых оценщиков. Помимо этого, банк, при принятии окончательного решения по кредитованию, учитывает не только правовые обстоятельства и риски, но также стоимость, по которой данный объект можно реализовать на рынке за короткий срок, то есть ликвидационную стоимость объекта залога. Данное обстоятельство является достаточным для включения ликвидационной стоимости в список показателей, входящих в отчет эксперта-оценщика.

Для устранения подобных негативных тенденций, по мнению автора, могут применяться следующие меры: использование общих для всех объективных методов отбора добросовестных оценщиков, усиление контроля за деятельностью СРО оценщиков по лицензированию экспертов-оценщиков, повышение уровня ответственности оценщиков, введение механизма трехстороннего договора, разработка единой методологии оценки для целей залога и кредитования, введение общего рейтинга экспертов для дополнительной мотивации оценщиков.

\section{Библиографический список}

1. Гражданский кодекс Российской Федерации (ред. от 29.12.2017) [Электронный ресурс]. - Режим доступа: Справочная правовая система «КонсультантПлюс» (дата обращения: 21.12.2017).

2. Федеральный закон от 29.07.1998 № 135-ФЗ (ред. от 29.07.2017) «Об оценочной деятельности в Российской Федерации» [Электронный ресурс]. - Режим доступа: Справочная правовая система «КонсультантПлюс» (дата обращения: 21.12.2017).

3. Классификатор услуг по оценке имущества. Основные положения. - Стандарт Российского общества оценщиков СТО POO 20-06-96.

4. Асаул, А. Н. Экономика недвижимости: Учебник для вузов / А. Н. Асаул. - СПб. : Питер, 2013. - 416 с.

5. Есипов, В. Е. Оценка бизнеса: Учебное пособие / В. Е. Есипов, Г. А. Маховикова. - СПб. : Питер, 2010. - 512 с.

6. Козловский, А. В. Управление имущественным комплексом строительных организаций: монография / А. В. Козловский. М. : Издательский дом ФГБОУ ВО «Государственный университет управления», 2011. - 144 с.

7. Официальный сайт РОО [Электронный ресурс]. - Режим доступа: http://sroroo.ru/about/ (дата обращения: 10.12.2017). References

1. Grazhdanskiy kodeks Rossiyskoi Federacii (red. ot 29.12.2017) [The Civil Code of the Russian Federation (as amended on December 29, 2017)]. Available at: Spravochnaja pravovaja sistema «Konsul'tantPljus» [ConsultantPlus legal reference system] (Accessed: 21 December 2017).

2. Federal'nyj zakon ot 29.07.1998 № 135-FZ (red. ot 29.07.2017) «Ob ocenochnoj deyatel'nosti v Rossijskoj Federacii» [Federal Law № 135-FZ of July 29, 1998 (as amended on July 29, 2017) «About valuation activities in the Russian Federation»]. Available at: Spravochnaja pravovaja sistema «Konsul'tantPljus» [ConsultantPlus legal reference system] (Accessed: 21 December 2017).

3. Klassifikator uslug po nocenke imuschestva. Osnovnie polozheniya - Standart Rossijskogo obshchestva ocenshchikov STO ROO [Classifier of offers for valuation of property. Basic provisions. Standard of the Russian Society of Appraisers 20-06-96].

4. Asaul A. N. Ekonomika nedvizhimosti. [Economics of real estate]. Saint-Petersburg, Piter, 2013. 416 p.

5. Esipov V. E., Makhovikova G.A. Ocenka Biznesa [Business evaluation]. Saint-Petersburg, Piter, 2010. 512 p.

6. Kozlovsky A. V. Upravlenie imuschestvennim kompleksom stroitel'nih organizaciy [Management of the property complex of constructional organizations]. - Moscow], 2011. - 144 pages.

7. Oficial'niy sait ROO [Official web site of the Russian Society of Appraisers]. Available at: http://sroroo.ru/about/] (Accessed: 10 December 2017). 